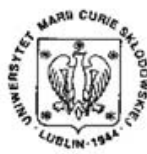

Annales UMCS Informatica AI XIII, 2 (2013) 29-36 DOI: $10.2478 / \mathrm{v} 10065-012-0044-9$

Annales UMCS

Informatica

Lublin-Polonia Sectio AI

http://www.annales.umcs.lublin.pl/

\title{
Performance test of network devices
}

\author{
Marek Bolanowski ${ }^{1 *}$, Andrzej Paszkiewicz ${ }^{1 \dagger}$ \\ ${ }^{1}$ Department of Distributed Systems, Rzeszów University of Technology, \\ al. Powstańców Warszawy 12, 35-959 Rzeszów, Poland
}

\begin{abstract}
Selection of components in contemporary computer networks is extremely important, not only because of the project budget but also because of the network performance. Therefore, it is necessary to perform tests before deploying devices. In this paper the authors show that the performance of test network devices is dependent on the nature of network traffic including its statistical properties. Also a new hybrid model of the system for testing the network device based on the q-additivity of traffic flows was proposed.
\end{abstract}

\section{Introduction}

One of the elements of an effective network devices choice for specific communication tasks is to determine their performance. Currently, there are several applications and hardware solutions which are used to generate the test traffic which load the examined network device. In this paper we check whether the statistical properties of the generated traffic have an impact on performance of the tested device. The purchase price of advanced, highly specialized network devices is very high. Such a purchase, without previous performance tests simulating the conditions in which the equipment will work, can be very risky for the project budget. Performance testing can make a preliminary assessment of the equipment suitability in the context of the challenges posed to it. Currently the measurements mainly relate to: one-way delay, maximum delay, delay variation, packet loss rate, bandwidth, file transfer time, resource consumption (cpu, memory, buffers, queue) $[1,2,3,4,5,6,7,8]$.

Modern methods of performance measurement can be divided into two types: theoretical, using mathematical models of network traffic and practical - based on research

*marekb@prz.edu.pl

†andrzejp@prz.edu.pl 
results. It is often necessary to use specialized measurement tools $[\mathbf{9}, \mathbf{1 0}]$. The authors of theoretical models consider only a simplified view of the real network, focusing on a small number of its parameters $[\mathbf{1 1}, \mathbf{1 2}]$. Currently used methodologies mainly focus on the topological aspects in performed tests, they often use the Gaussian distribution, analyze device performance from the point of view of a few chosen traffic parameters $[13,14]$. However, it is necessary to check whether the holistic traffic has an impact on the test results of particular parameters of a device.

\section{Test traffic generation}

Generation of traffic loading the tested device is often based on quantitative summation of the partial streams, assuming a simple additivity of information streams [8]. Let us assume that the intensity of streams flowing on the path $i$ will be denoted as $N_{P_{i}}$. According to the classical approach, the total intensity of the flow will be $S N$ :

$$
S N=N_{P_{1}}+N_{P_{2}}+\ldots+N_{P_{i}} .
$$

In this case, the use of non-equilibrium dynamics is more appropriate than the use, of non-extensive q-algebra which derives from the Tsallis's entropy $[\mathbf{1 5}, \mathbf{1 6}]$. It is based on $q$-operations which lead to generalizations of the classic algebra. From the point of view of our considerations, the most interesting is $q$-sum of two streams $x$ and $y$ which is based on a non-extensive operator of sum $\oplus_{q}$ defined as:

$$
x \oplus_{q} y=x+y+(1-q) x y .
$$

Equation (2) shows that the $q$-sum contains an equilibrium, additive term $(x+y)$ and dynamic non-equilibrium term $(1-q) x y$ which symbolizes non-extensivity and the sensitivity to initial conditions $[\mathbf{1 7}, \mathbf{1 8}]$. Taking these assumptions into account, we can conclude that the equation (1) is only a special case of the sum of simple streams with no memory effect. It is therefore purposeful to examine the sensitivity of the device to test flows which have different thermodynamic properties. Research of the real network traffic detects the internal correlation in streams $[\mathbf{1 9}, \mathbf{2 0}]$. The development of new network services cause that traffic is characterized by a much stronger, long-range correlation. Accordingly, new models of streams with a long memory were created. To analyze statistical, properties which are of interest to us the Hurst exponent is used. Hurst exponent $(H)$ is an indicator used, inter alia, to classify time series. On its basis, it is possible to distinguish a random from non-random series. Its value may be within the range from 0 to 1 . It is possible to define three ranges of the Hurst exponent: $H=0.5$ - the series are random and uncorrelated events, $0 \leq H<0.5$ - the series are antipersistent or ergodic, this range is very rare in the case of real world (real network traffic) time series, $0.5<H<1$, the series are persistent, have a memory effect, a lot of real world time series have such a value of $H[\mathbf{6}, \mathbf{1 9}, \mathbf{2 0}]$.

The tests will be performed on a number of network devices with the connection scheme presented in Fig. 1. 


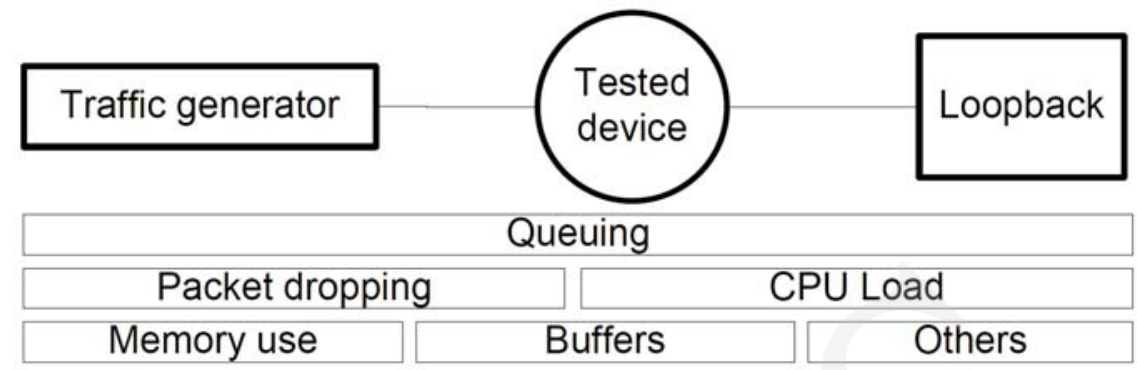

Fig. 1. Stress test - connection diagram.

\section{$3 \quad$ Results of the stress tests}

In this scenario, on the tested network device mechanism for traffic shaping $(\mathrm{Q} \circ \mathrm{S})$ was implemented and then the queues and CPU load were analyzed. The traffic was generated at a constant speed equal to $10 \mathrm{~Gb} / \mathrm{s}$ and came from three different sources.

\subsection{Traffic generation using the hardware generator}

In this section the network devices were tested using the traffic coming from the hardware generator (JDSU) in which the streams and protocol parameters were defined up to 4 layers of the ISO/OSI model and varied pseudo-randomly. The JDSU generated at the same time up to 4096 streams that totally gives traffic of $10 \mathrm{~Gb} / \mathrm{s}$.

The parameters of generated traffic are shown in Fig. 2 and Table 1.

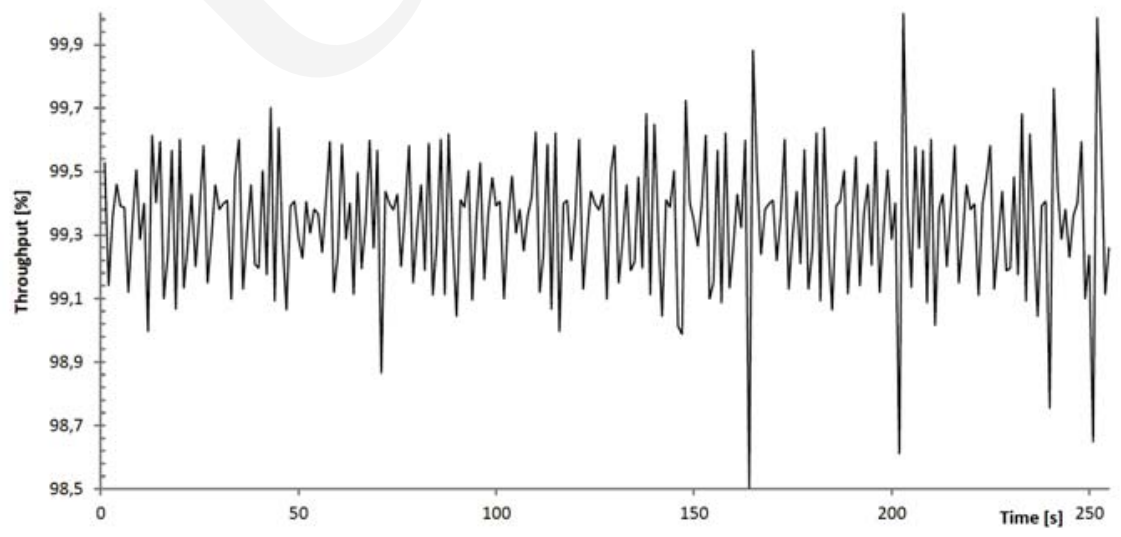

Fig. 2. Traffic generated with the hardware generator. The percentage of bandwidth utilization.

The traffic generated with the hardware generator JDSU is a series with a constant level of fluctuation. Traffic generated in this manner does not reflect fully the conditions that occur in real networks. The $H$ exponent for particular process parameters received 
Pobrane z czasopisma Annales AI- Informatica http://ai.annales.umcs.pl

Data: 26/04/2023 13:13:16

Table 1

\begin{tabular}{|c|c|c|c|c|c|c|c|c|c|}
\hline \multicolumn{2}{|c|}{ Throughput utilization } & \multicolumn{2}{|c|}{ Packet per sec } & \multicolumn{2}{|c|}{ TCP per sec } & \multicolumn{2}{|c|}{ UDP per sec } & \multicolumn{2}{|c|}{ Packet size } \\
\hline $\mathrm{H}$ & R2 & $\mathrm{H}$ & R2 & $\mathrm{H}$ & R2 & H & R2 & $\mathrm{H}$ & R2 \\
\hline 0.227 & $\begin{array}{c}\text { from } 0.034 \text { to } \\
0.170^{*}\end{array}$ & 0.103 & $\begin{array}{c}\text { from } 0.022 \text { to } \\
0.313^{*}\end{array}$ & 0.102 & $\begin{array}{c}\text { from } 0.016 \text { to } \\
0.289^{*}\end{array}$ & 0.114 & $\begin{array}{l}\text { from } 0.017 \\
\text { to } 0.302^{*}\end{array}$ & 0.099 & $\begin{array}{c}\text { from } 0.023 \\
\text { to } 0.321\end{array}$ \\
\hline
\end{tabular}

the minimum value for the average packet size $(H=0.099)$ and the maximum for the percentage of the bandwidth use $(H=0.227)$. Specific Hurst exponents for the generated traffic are similar, within the range $0-0.5$, which indicates that there is an antipersistent or ergodic time series.

Tested device was able to smoothly manage the traffic, the CPU load increase was imperceptible, the band was formed accordance with the assumptions of the QOS rules. The main reason for such smooth traffic service by the device appears to be a simple character of generated traffic in which there were no changes of the characteristics during the entire performance test.

\subsection{Traffic generation using the software generator}

In this section the network devices were tested using the traffic coming from the software generator (Iperf) in which the streams and protocol parameters were defined up to 4 layers of the ISO/OSI, totally gives traffic of $10 \mathrm{~Gb} / \mathrm{s}$.

The parameters of generated traffic are shown in Fig. 3 and Table 2.

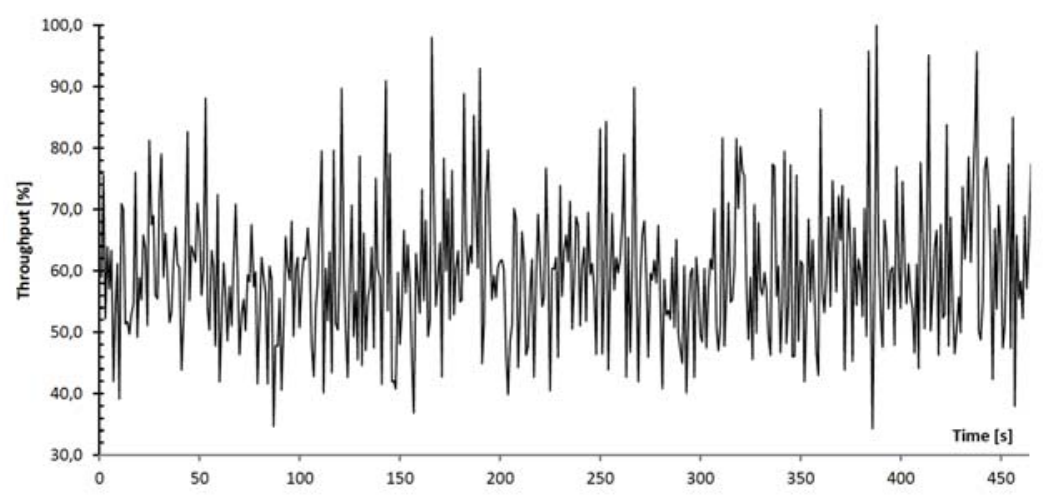

Fig. 3. Traffic generated with the software generator. The percentage of bandwidth utilization.

The traffic generated with Iperf program traffic generator is characterized by a greater change than it was in the case of JDSU. The $H$ exponent for particular process 
Pobrane z czasopisma Annales AI- Informatica http://ai.annales.umcs.pl

Data: 26/04/2023 13:13:16

Table 2

\begin{tabular}{|c|c|c|c|c|c|c|c|c|c|}
\hline \multicolumn{2}{|c|}{ Throughput utilisation } & \multicolumn{2}{|c|}{ Packet per sec } & \multicolumn{2}{|c|}{ TCP per sec } & \multicolumn{2}{|c|}{ UDP per sec } & \multicolumn{2}{|c|}{ Packet size } \\
\hline $\mathrm{H}$ & $R^{2}$ & $\mathrm{H}$ & $R^{2}$ & $\mathrm{H}$ & $R^{2}$ & $\mathrm{H}$ & $\mathrm{R}^{2}$ & $\mathrm{H}$ & $\mathrm{R}^{2}$ \\
\hline 0.336 & $\begin{array}{c}\text { from } 0.061 \text { to } \\
0.347^{*}\end{array}$ & 0.366 & $\begin{array}{c}\text { from } 0.220 \text { to } \\
0.510^{*}\end{array}$ & 0.492 & $\begin{array}{c}\text { from } 0.175 \text { to } \\
0.510^{*}\end{array}$ & 0.287 & $\begin{array}{l}\text { from } 0.247 \\
\text { to } 0.547^{*}\end{array}$ & 0.233 & $\begin{array}{c}\text { from } 0.177 \\
\text { to } 0.514^{*}\end{array}$ \\
\hline
\end{tabular}

parameters received the minimum value for the average packet size $(H=0.233)$ and the maximum for the number of TCP packets $(H=0.492)$. The values of the exponents $\mathrm{H}$ are greater than those which characterized the traffic form JDSU hardware, but still $H<0.5$. The series are defined as "returning to the mean". During the test band was formed accordance with the assumptions of the QOS rules. In comparison to the test with the JDSU generator, the network device CPU load increased in the range of 15 to $24 \%$.

\subsection{Testing network device with a real traffic}

In this section the network devices were tested using the real traffic coming from the real computer network. Bandwidth saturation was significantly lower than previous cases and ranged at $1 \mathrm{~Gb} / \mathrm{s}$.

The parameters of the generated traffic are shown in Fig. 4 and Table 3.

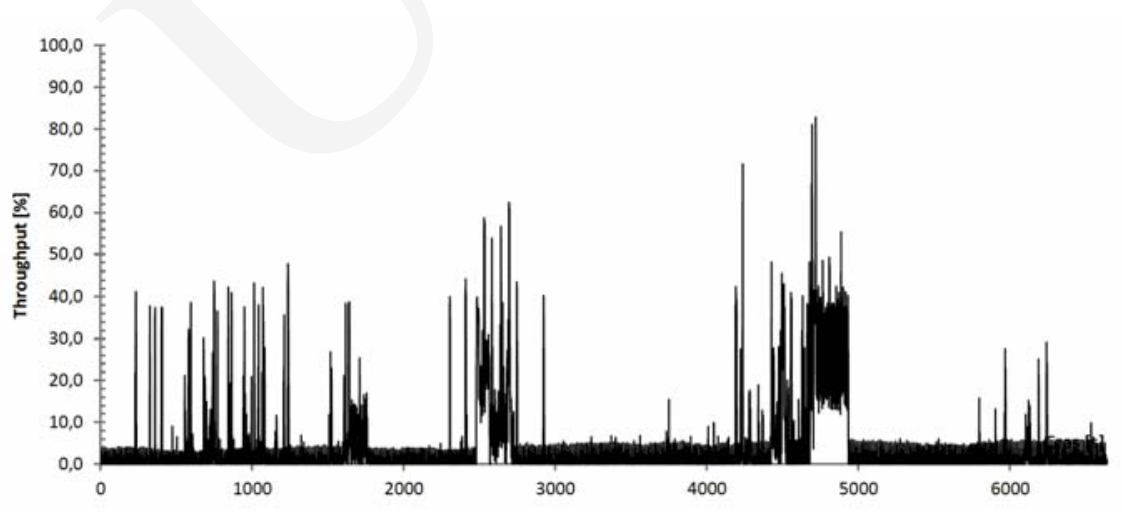

Fig. 4. The real network traffic. The percentage of bandwidth utilization.

Traffic from the real network has a high complexity. The frequent and major changes in its characteristics can be found. In the case of traffic from a real network $H$ exponent for particular process parameters received the minimum value for the number of TCP packets $(H=0.569)$ and the maximum for the number of UDP $(H=0.684)$. For this traffic the value of the exponent $H>0.5$, which indicates that it is persistent, keeping a positive correlation between states, indicates the existence of a trend. It 
Pobrane z czasopisma Annales AI- Informatica http://ai.annales.umcs.pl

Data: 26/04/2023 13:13:16

Table 3

\begin{tabular}{|c|c|c|c|c|c|c|c|c|c|}
\hline \multicolumn{2}{|c|}{ Throughput utilisation } & \multicolumn{2}{|c|}{ Packet per sec } & \multicolumn{2}{|c|}{ TCP per sec } & \multicolumn{2}{|c|}{ UDP per sec } & \multicolumn{2}{|c|}{ Packet size } \\
\hline $\mathrm{H}$ & $R^{2}$ & $\mathrm{H}$ & $R^{2}$ & $\mathrm{H}$ & $R^{2}$ & $\mathrm{H}$ & $R^{2}$ & $\mathrm{H}$ & $R^{2}$ \\
\hline 0.573 & $\begin{array}{c}\text { from } 0.684 \text { to } \\
0.867^{*}\end{array}$ & 0.636 & $\begin{array}{c}\text { from } 0.514 \text { to } \\
0.8191^{*}\end{array}$ & 0.569 & $\begin{array}{c}\text { from } 0.658 \\
\text { to } 0.857^{*}\end{array}$ & 0.684 & $\begin{array}{c}\text { from } 0.124 \\
\text { to } 0.664^{*}\end{array}$ & 0.625 & $\begin{array}{l}\text { from } 0.651 \\
\text { to } 0.806^{*}\end{array}$ \\
\hline
\end{tabular}

can be said that this traffic has a long-term memory. During the test a band was not formed in accordance with the assumptions of the QOS rules (QOS did not work properly). Compared to the test with the JDSU generator, the network device CPU load increased in the range of 20 to $35 \%$. Then on the test network device the QOS algorithm was changed - from standard to Three-colour Marking. After this change the QOS worked properly.

\section{Conclusions}

The research identified the relationship between the statistical properties of the traffic and the load of tested device components in particular QOS mechanisms. This allows to conclude that apart from quantitative tests (for example the number of entries in the routing table, the number of VPN sessions supported at the same time, the number of supported queues, ...) the statistical parameter of the traffic should be taken into consideration. The research found that the test traffic originating from a real network led to overload the standard QOS mechanism, and enforced the use of TCM. Taking into account the paper [18] and in particular, the properties of equation (2) the authors propose a new model for network devices stress tests using the hybrid model shown in Fig. 5 .

The use of real traffic, which is optimal for testing new equipment is subject to many restrictions: problems in its recording and playback, storage problems, the confidentiality of the data. The traffic from hardware and software generators is relatively simple, contains no memory effect and poorly reflects the explosive nature of the TCP protocol. However, it can easily provide significant load to switching matrix (or routing engine) of tested device. On the other hand, the real traffic allows to provide to a test stream a non-extensive long-term nature of the events occurring in the real network environments. Therefore, the use of the model shown in Fig. 5 allows to control the components of the test traffic (which is the q-sum of streams from different generators and real traffic) to get closer to the actual conditions in which the tested device will operate. The task of the External Data Collector and Analyzer module is to gather test results from all devices and make recapitulation. In the further work the authors want to focus on developing software traffic generator that will create traffic with given statistical parameters. 


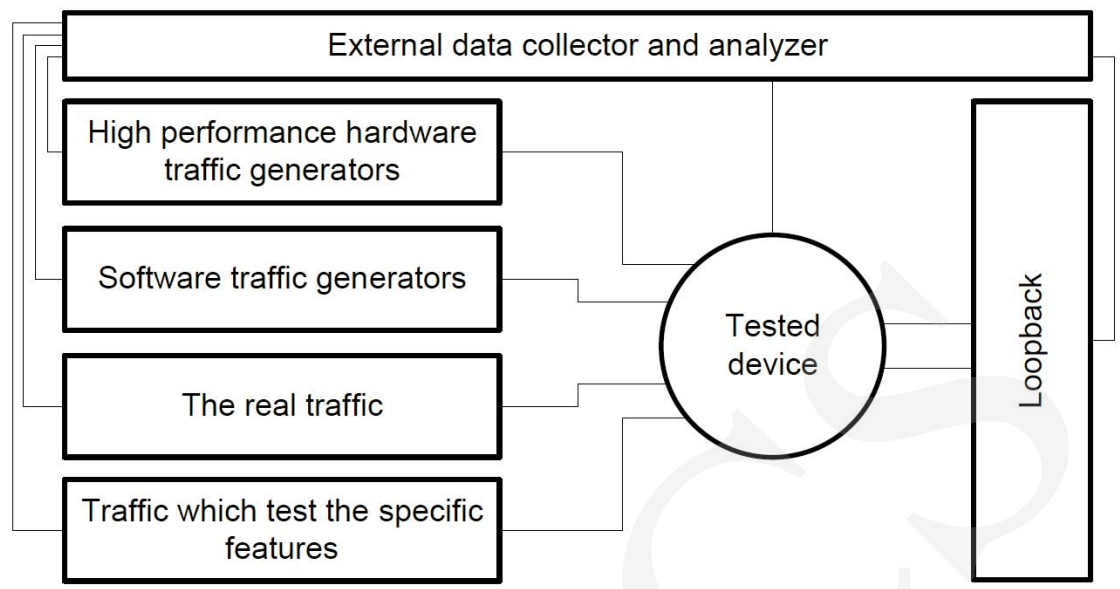

Fig. 5. The hybrid model of the system for testing the network device.

\section{References}

[1] Comer D. E., Sieci komputerowe TCP/IP. 1, Zasady protokoły i architektura, Wydawnictwa Naukowo-Techniczne, Warszawa (1998).

[2] Nowicki K., Woźniak J., Sieci LAN, MAN i WAN - protokoły komunikacyjne, Wydawnictwo Fundacji Postępu Telekomunikacji, Kraków (2000).

[3] Pytel K., Systemy operacyjne i sieci komputerowe, Wydawnictwa Szkolne i Pedagogiczne, Warszawa (2010).

[4] Hassan M., Jain R., Wysoko wydajne sieci TCP/IP, Wydawnictwo Helion, Gliwice (2004).

[5] Grzech A., Sterowanie ruchem w sieciach teleinformatycznych, Oficyna Wydawnicza Politechniki Wrocławskiej, Wrocław (2002).

[6] Kolbusz J., Paszczyński S., Comparison of traffic self-similarity in two different computer networks, Tools of Information Technology, Procedings of the 2-nd conference, Rzeszów, Poland, 21 September (2007): 85.

[7] http://www.ixiacom.com

[8] http://www.jdsu.com

[9] Zatwarnicka A., Sposoby szacowania czasu transmisji pakietów przez Internet, Wysokowydajne sieci komputerowe. Zastosowania i bezpieczeństwo, Wydawnictwa Komunikacji i Łączności, Warszawa (2005).

[10] EtherNet/IP Performance Workgroup, Performance Terminology for EtherNet/IP Devices, EtherNet/IP Implementors Workshop (2004).

[11] Bradner S., Benchmarking Terminology for Network Interconnection Devices, Internet Engineering Task Force (IETF), RFC 1242 (1991).

[12] Bradner S., McQuaid J., Benchmarking Methodology for Network Interconnection Devices, Internet Engineering Task Force (IETF), RFC 2544 (1999).

[13] BreakingPoint, Rethink Firewall Testing A Methodology to measure the performance, security, and stability of firewalls under realistic conditions, BreakingPoint (2010).

[14] Jiang D., Fei M., Wang H., Li T., Wireless Network Performance Test in Hybrid Wired Wireless Network System, Proceedings of the 8th World Congress On Intelligent Control and Automation June 21-25 2011, Taipei, Taiwan (2011).

[15] Borges P. B., A possible deformed algebra and calculus inspired in nonextensive thermostatistics, Physica A 340 (2004): 95. 
Pobrane z czasopisma Annales AI- Informatica http://ai.annales.umcs.pl

Data: 26/04/2023 13:13:16

[16] Nivanen L., Le Méhauté A., Wang Q.A., Generalized algebra within a nonextensive statistics, Reports on Mathematical Physics 52 (2003): 437.

[17] Tsallis C., Plastino A. R., Zheng W. M., Power-law sensitivity to initial conditions, Chaos, Solitons \& Fractals 8 (1997): 885.

[18] Grabowski F., Nonextensive model of self-organizing systems, Complexity, Wiley (2013).

[19] Jęruś S., Modele multifraktalne natężenia ruchu sieciowego z uwzględnieniem samopodobieństwa statystycznego, Telekomunikacja Cyfrowa - Technologie i Usługi, 4 (2001/2002).

[20] Wójcicki R., Nowe metody modelowania samopodobnego ruchu w sieciach w oparciu o procesy Poissona z markowską modulacją, Studia Informatica 24( 2(63)) (2005). 